\title{
Bias in the Critique of Arab Architecture
}

\author{
Hasanain A. Karbol ${ }^{1 *}$, Sarah M. Al-Saadi ${ }^{1}$, Basim H. Almajidi ${ }^{2}$ \\ ${ }^{1}$ Department of Architecture, Faculty of Engineering, University of Kufa, Najaf 54001, Iraq \\ ${ }^{2}$ Department of Architecture, University of Technology, Baghdad 10045, Iraq
}

Corresponding Author Email: hasanaina.karbol@uokufa.edu.iq

https://doi.org/10.18280/ijdne.160512

Received: 24 August 2021

Accepted: 24 September 2021

\section{Keywords:}

bias, criticism, local identity, contemporary

Arab architecture

\begin{abstract}
The research derives its significance from the importance of the subject of architectural criticism, and what it reflects on the reality of contemporary architecture and local identity in the Arab region in light of the changing political and economic ideas. From this point of view, the research problem can be summarized as: The extent of the comprehensiveness of previous studies of the relationship of bias to architectural criticism and determining its characteristics and types as a mechanism of criticism in contemporary Arab architecture. To address the research problem, the goal of the research was determined by building a theoretical framework to understand how to release critical judgments within the concept of bias, and to access the mechanisms that measure criticism in contemporary Arab architecture based on the research hypothesis that states: The intellectual features in architectural criticism are determined through a set of characteristics and concepts associated with the concept of bias.
\end{abstract}

\section{INTRODUCTION}

The concept of bias is one of the central concepts among specialists and decision makers in Arab culture in general, through the use of several terms related to customs and traditions, the most important of which is local identity, and other similar concepts that are commonly used in Arab thought. It makes no sense to talk about these meanings without being preceded by an acknowledgment of the cognitive bias towards the West. Architecture is a broad field that is closely related to these cultural and spatial concepts, which reflect the epistemological visions of the prevailing and ruling traditional values, and the exotic Western architectural styles.

Despite this, Arab architecture, in turn, did not escape its bias towards Western characteristics as a result of several factors, the most important of which is the import of educational curricula, local governing laws, and special engineering programs in the work of designers, which collectively led to the shift towards the use of modernist materials, which in turn was reflected in the style Arab architecture and later criticism bias. In light of the above, we can ask the following sub-questions:

(1) What is the relationship between Arab and local architecture and critical bias?

(2) Are there characteristics that highlight the extent of bias in Arab architecture?

To address the research problem, the research objective was to build a theoretical framework to understand how to make critical judgments within the concept of bias and its impact on the products of Arab architecture, and then study the extent to which they can be achieved by testing the research hypothesis, which states: Intellectual features in architectural criticism are determined by a set of characteristics and concepts associated with bias.

\section{RESEARCH METHODOLOGY}

The research methodology depends on the sequence of the following steps:

(1) Creating a search database through a survey of studies into the concept of bias.

(2) Analyzing theoretical research information to build a summary through the intersection of key concepts related to bias values in architecture.

(3) Identifying Arab architectural examples, study them according to research criteria, and compare their critics.

(4) Applying the criterion of bias to the selected examples.

(5) Establishing the conclusions.

\section{THE COGNITIVE AND CONCEPTUAL FRAMEWORK OF BIAS}

\subsection{Defining bias linguistically and idiomatically}

According to Kahneman (2002), bias is a judgment in making improper decisions that occurs in some cases, causing distortion of sensory perception or expressing inaccurate opinions and interpretations that are irrational and far from logic [1]. While it was stated in Arif's study (2002) that it is focusing on the self and closing in on it and seeing the other through it and comparing with it, which means the complete negation of the other outside the scope of history, existence or science, and seeking to replace its essence and identity with data consistent with the self and its goals by eliminating its uniqueness and privacy and reintegrating it into the system which the biased self sees as optimal according to its perspective on man and life [2].

Bias in this concept means that the curricula, no matter how different their fields of knowledge, especially in the field of 
humanities, are an integrated system, including procedural tools and the cognitive vision that frames them. Hence, bias is multiple following the multiplicity of types of knowledge, as it is relative and subject to permanent development and continuous change, and thus it does not accept the absolute and universal characteristics, because it is not transcendent to the historical and civilizational particularities that created it, which means that its procedural efficiency is limited by time and place.

In the "Dictionary of Social Sciences Terminology", bias represents a mental tendency to judge things before they fully stand for their truth, under the influence of past experiences or some subjective emotional factors that cause an error in judgment. A biased sample is designed in such a way that it is not representative of the original community from which it was drawn. The term biased response is also used in this context to refer to research procedures that push researchers to provide false information [3].

The author of the "Al-Shamil" dictionary of terms lists different types of bias: positive bias, negative bias, decreasing bias, experimental bias, and out-of-sample bias, each according to the field of knowledge, or the type of existing relationship and interaction. Then all of them are gathered by a regulating behavioral thread that formulates the same meanings. As it is: an incorrect estimate, distortion or alteration that affects the results of the research and not giving all units of the community equal opportunities to be represented in the calculated sample, which makes them distinct and not honestly representative of the community from which it was withdrawn [4].

There are many studies that dealt with bias as an existential phenomenon with multiple cases: individual, social, human, and scientific. Bias could be found in various fields: psychological, educational, linguistic, hermeneutical, and political fields. Among the most prominent problems of bias that attract writing around is the Eurocentrism and bias towards Western culture. The emergence of new critical works, which sought to break the dominance of ahistorical centralities, and contributed to the production of new critical classifications such as post-colonialism, deconstruction, and the concept of the other.

\subsection{Knowledge bias}

In his study, Al-Hariri (2010) focused on the concept of bias through his criticism of scientific research, as he defined it as "the tendency or preference for a decision or choice without the right justifications behind it". The concept of bias was clarified through two main axes, namely, the method of data collection and the selection of the research sample, where he emphasized the researcher to be careful in choosing the research sample so that the opportunity is equal for all individuals or community units to become one of the samples that is chosen to conduct the study on it. The lack of equal opportunity or unfairness in determining the sample may lead to problems that may weaken the significance of the research and may prevent the researcher from being able to generalize any results he reaches from his study to the community [5].

Al-Hariri (year) also mentioned a set of reasons that may lead to the problem of bias when choosing a research sample, which are [5]:

(1) Not to choose the sample randomly, as the random selection is very important to ensure equal opportunities for individuals or units of the community to become part of the research sample. However, some researchers sometimes select members of the community who may be relevant to them for ease of contact and obtaining data for the study from them. At other times, the researcher may choose a group of multiple research groups that do not alone represent the research community.

(2) Not obtaining data from all members of the sample, as the researcher may not be able to obtain data from all members of the selected sample and is satisfied with the information he obtained, and after the end of the study, he may generalize the results of the research to the research community without making sure that the sample is correct.

As for the bias in the method of data collection, it may occur due to:

(1) Inaccuracy of the method of data collection or the use of unclear questions or questions that may suggest the correct answers or any questions that may lead a person to prefer answering the following questions in some way.

(2) The researcher chooses a data collection method through which some sample members cannot provide data, either because some of the requirements of this method are not available, or because the sample members do not know the method of providing data through this unknown method.

\subsection{Bias between positive and negative}

El-Messiri presented a critique of a central question: What are the most important biases of Western modernity?

He used a new term in the criticism of Western civilization in its epistemological dimensions and wanted it to be a tool and a means to identify Western biases inherent in the curricula and tools used by Arab researchers in their studies, which in his opinion constitutes the most common and dangerous biases. Many see that Western values are universal values, and they adopt them without realizing their Western specificity, whether this adoption is consciously or unconsciously.

El-Messiri believes that the term modernity is one of the most important phenomena produced by Western civilization, which reflects its biases. According to El-Messiri, modernity begins from the end of the First World War until the midsixties of the twentieth century. He defines it as the adoption of science, technology and the mind as the only mechanisms for dealing with reality [6].

As for the bias of Al-Bazi'i, he referred to privacy as one of the most prominent meanings of local identity, that is, not in its negative concept, which means for some people the difference that includes the meaning of interruption and isolation. Therefore, the specificity of a culture or civilization is a form of divergence from other cultures and civilizations, in addition to another negative meaning which is the claim of excellence, that is, not in terms of mere difference, but rather in terms of distinction that involves superiority. Privacy for him means nothing but relative difference based on a set of cultural features that resulted from historical accumulations, environmental and societal interactions, in addition to intellectual and creative endeavors at the level of individuals.

Al-Bazi'i asserts that the specificity of Western critical approaches, theories and concepts is double: the first does not 
belong to the creators of these theories, approaches and concepts, and their starting point is Western civilization as their reference, while the second is the privacy of individuals themselves, the producers of these theories and approaches. What Al-Bazghi meant is the specificity of the theories, methods, and literary criticism concepts produced by Western civilization, a phenomenon that stems from the privacy of individuals who produce theories and influence them, just as it stems from the greater specificity, represented by the civilization as a whole, from which many Western intellectual products originated and returned, as an extension of what the titles of the books announced, and access to in-depth specialized studies [7].

\subsection{Bias and criticism}

The most important biases addressed in critical studies can be listed based on a number of determinants associated with groups or individuals as follows:

(1) Confirmation Bias: People tend to stay away from individuals, groups, and news sources that make them feel uncomfortable and secure about their views. Behavioral psychologist B. F. Skinner calls this phenomenon (Cognitive Dissonance) [8], as it can be seen as a preferential behavior that leads to confirmation bias. It is an unconscious act that causes a person to embrace the views that feed pre-existing ones. This action results in rejecting and ignoring other opinions, no matter how valid they are.

(2) In-group Bias: It is a manifestation of innate tribal tendencies. This bias has to do with the hormone "oxytocin", as this neurotransmitter helps a person to establish stronger bonds with members of his group, but it has an opposite effect on his relationship with strangers, as it makes him suspicious, where one group is overvalued at the expense of another [9].

(3) Status-Quo Bias: People tend to be afraid of change, which often leads them to prefer options that keep things as they are or choose to change as little as possible. But the downside of this bias is that it makes other options inferior to them as necessarily wrong [10].

(4) Bandwagon Bias: It is to go along with the current that everyone is moving towards despite the lack of awareness of it, where the individual mind stops working, and switches to a state (groupthink), the crowd does not have to be large, but can include small groups such as family, co-workers or friends. This causes behaviors and norms to spread across groups of individuals, regardless of evidence or motivation [11].

(5) Projection Bias: A person's tendency to assume that most people think exactly like him, and this leads him to project his qualities and his way of thinking on them, despite the lack of any justification for this, and this is also called the (False Consensus Bias). This bias is because the individual wants to convince himself that he is typical, assuming that there is a consensus on an issue, while there may not be any [12].

(6) Anchoring Effect Bias: Also known as relativistic trap bias. This concept expresses the tendency to compare several things within the scope of a finite set at the level of the part, neglecting the total range at the level of the whole [13].

(7) Frequency Illusion bias: When an individual perceives a word, a name or a meaning for the first time, then soon he sees and hears it everywhere [14].

(8) Attentional Bias: When a person focuses his or her attention on one or two options, even though there are other options on the table [15].

(9) Availability Heuristic Bias: This is when people exaggerate the value of a piece of information because it is available to them [16].

(10) Choice-supportive Bias: Occurs when a person begins to think about the positives of a decision or choice made without considering its disadvantages, such as mentioning the importance of critical articles that are published without regard to any negative impact that may occur because of them [17].

(11) Bias blind spots: If you can't see your cognitive biases, it's because you have another kind of bias that is your blind spot. Each of us thinks that he is not biased as others see him, this is the bias itself [18].

(12) Conservatism Bias: When people find it easier to believe old evidence than new evidence on a topic, people tend not to accept the new easily [19].

(13) Curse of knowledge: This is the case of a man who knows too much. When people are too intelligent, or too highly educated, it becomes difficult for them to understand and communicate with the common people [20].

(14) Outcome Bias: This is famous for saying "the end justifies the means," but it is here in a more comprehensive sense. Some are interested in succeeding in a subject rather than studying and understanding it, so they depend on any means to achieve the goal [21].

(15) Survivorship Bias: This error results from focusing on models and projects that lasted for a long time, which makes a person judge them wrongly, as he does not take into account the models that have not been successful [22].

(16) Stereotyping: It is the prior portrayal of a group of people or a certain social system as having certain characteristics without knowing whether they are or not. Once you know that so-and-so is from the family of soand-so, or a group, or such-and-such a city or country, a person finds himself building an image of this person, and these stereotypes are often wrong, and cannot be generalized to other individuals [23].

(17) Appeal to authority: Some people depend, in various aspects of their lives, on the opinions and expectations of those they consider to be experts in a certain field, to avoid bearing responsibility for the decision. The power here is not necessarily political power [24].

(18) Salience bias: The individual usually focuses on what appears to be evident in a person or thing and neglects other characteristics due to the severity of his appearance and clarity [25].

\subsection{Bias and Arab architecture}

Architecture has become an important aspect of society and an essential pillar of its culture, and a true reflection of its thought and values. Like others, it was affected by the current of Westernization, which lost a large part of its content, and consequently its formation, so it was conflicting and inconsistent. So far, the Arab countries have not succeeded in reaching an appropriate formulation for their culture, and the establishment of social rules specific to their societies, the lifestyle of their citizens, and their local architectural style, 
which is due, according to El-Messiri [26]:

(1) Fascination with Western civilization:

At the end of the nineteenth century, Westernization currents came to the Islamic nation through Western campaigns that brought not only its modern organized army but another more dangerous army, an army of Western scholars who studied and analyzed various aspects of life in colonial countries. If we take Egypt, for example, we find that after the French left it after nearly three years, the Egyptian society woke up to a sense of the strength of this West, and was fascinated by its progress, which soon became overwhelmed by an underlying feeling of inferiority. After that, Egypt surrendered to the British military occupation, which lasted for about seventy years, and The Western era has produced the tide of modernity based on choosing the general Western civilizational pattern, that option is still valid today. As in the modernity trilogy, which was established by the Egyptian architect Mahmoud Riadh (the year) in the context of Tahrir Square in Cairo, which consists of three buildings: the Arab League building in 1955, the headquarters building of the Socialist Union in 1959, and the Hilton Nile Hotel in 1959, which are considered of the most important buildings in the vicinity of Tahrir Square, which followed the modern Western style in its design. As in Figure 1.

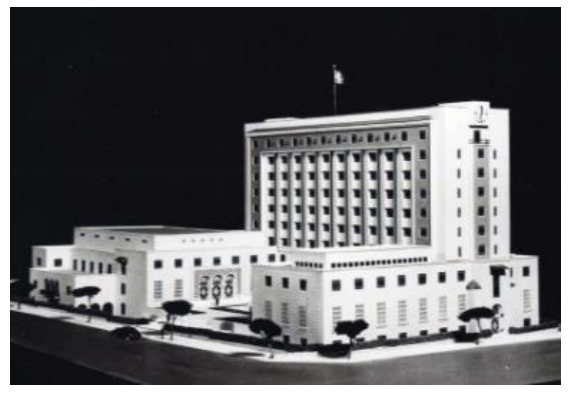

a: Arab League Building

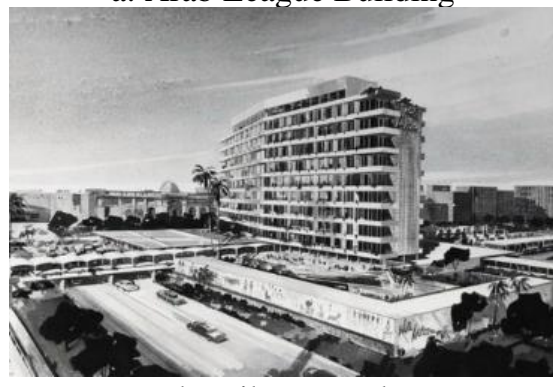

b: Hilton Hotel

Figure 1. Modernist buildings in Egypt

(2) The educational process and the lack of studies and references:

Western thought is almost the only thought proposed in the educational curricula for students of architectural studies in the Arab and Islamic world, without considering the origins of this thought, and its relevance to the Arab community in general. There is an almost complete transfer of teaching methods from the colleges of architecture in the West, as well as a transfer of the curricula and books under study so that Western thought and curriculum are the only curricula presented to students in Islamic countries, as a result of the Scholarship policy.

When the transfer nation is the lower party and the weakest side, it loses its ability to select, but if the transferring party is the highest and the strongest with its original civilizational provision, then this provision becomes a barrier from deterioration in imitation and dissolution.
These indicators have appeared clearly since the beginning of this century when we find that European architects have succeeded in pushing the global community, including the Islamic countries, to adopt an architectural style called: (international style) under the pretext of unifying the way of architectural thinking, and the method of solving architectural and planning problems. Architects in various countries of the world have adopted and applied the (international style) and that is a fascination with its goals and foundations on the one hand, and fascination with the civilization of Western societies on the other hand. The most important objectives of the international style were [27]:

(1) Abolishing curved lines and replacing them with straight lines and right angles to ensure simplicity, clarity and ease of perception, as well as ease of automated production.

(2) Exploitation of technology in architectural forms, for example, exterior facades clad with prefabricated pans using materials, most of which are automated, such as glass, plastic, aluminum, iron, and others, which achieves speed in completion. For example, it is possible to cover a building facade with an average height of thirty floors in several days does not exceed the fingers of one hand.

According to the writer Ali Abdel Raouf (2016) [28], architecture is a cultural product par excellence. To confirm this proposition, he asks what is culture? As he considers it a distinct path to the life of the group, and an integrated pattern of the life of its members, which confirms the human quality in the human race, and consists of values, beliefs, standards, rational interpretations, symbols, ideologies, and similar mental products. It refers to the overall style of life of a people, the personal relationships between its members as well as their orientations. This complex concept of culture includes cultural biases, social relations, patterns or ways of life. Cultural bias refers that shared values and beliefs, and social relationships are patterns of interpersonal relationships between individuals, while lifestyle is a living combination of social relationships and cultural bias.

Abdel Raouf [28] also explained the danger of complete bias towards Western taste in architecture and art. Such a decision taken by the Arab citizen portends the extinction of Islamic arts because the market does not demand them, so the craftsmen turn to those that generate a greater return, or the craftsman turns away from Islamic arts for easier and less decorative arts, effortless and easier to market. Complete replacement is not impossible, but it may take long periods and requires continuous awareness and planning for replacement, and it is easier when starting to furnish the place in the Islamic style to be from the beginning, especially with the presence of innovations that employ Islamic arts in furniture and interior architecture while reducing the decoration or costly excessive inscriptions. This is what Abdel Halim Ibrahim, a professor of architecture at Cairo University, calls transformational interior architecture that attempts to integrate Islamic styles and arts with contemporary ones instead of completely replacing them. This trend can also be achieved in external architecture when the visual formulation of the buildings turns into a rich, harmonious dialogue between reformulated and creative heritage values with a contemporary proposal and modern items that is consistent and compatible with the traditional authentic. The result will be architectural innovations that are born of the era but are highly attached to values from the past 
without falling into the trap of naive imitation or superficial copying [28].

\subsection{Bias and local identity}

The research deals with a set of studies that referred to the concept of critical bias, as follows:

Al-Massiri is considered one of the most prominent people who dealt with the concept of bias in Arab culture, and he established two rules that help in understanding and distinguishing bias [29]:

(1) The first rule: Bias is inevitable because it is linked to the very structure of the human mind. This mind is not a machine, but rather an active one that perceives reality through a model, excluding some details and leaving others. It is at the core of the human condition, as everything human contains a measure of uniqueness and subjectivity, and then bias.

(2) The second rule: Bias may be inevitable, but it is not final, meaning that bias is not a defect or shortcoming, but on the contrary, it can be stripped of its negative meanings. The human language, despite its limitations, can build cognitive models out of a special civilized experience, and at the same time helps to deal with oneself and the other. In the sense, that bias is not final, but the final is common humanity and its moral values.

The researcher also distinguished between the most important types of bias used in criticism methods, including:

\section{(1) Total Bias and Partial Bias:}

The total bias is for the researcher to be biased towards all aspects of the cognitive model that he adopts with all its entanglements and implications. Examples of this type of bias abound in our ancient, modern and contemporary Arab intellectual discourse. Many "Muslim philosophers" biased toward Aristotle's philosophy and logic, and many pioneers of the Arab Renaissance and modern criticism favored the Western civilizational model, its sciences, philosophy, literature, art, and concepts. Partial bias is a bias towards one component of the model. This type of bias can be the result of the researcher's ignorance of the cognitive model that he adopts, but it can also be a conscious act carried out by a selfconfident person who has a clear identity that revolves within it, stands on its ground, and has his specific biases, then looks at the world and takes from it what he wants, and reformulates it following his criteria, meaning that this person is not against the newcomer, not against benefiting from the other, not against being open to him, but against someone putting an imported scale in his hand to weigh things, against speaking about himself in the third person, and against closing the door of diligence for the other.

\section{(2) Conscious and unconscious (latent) bias:}

Conscious bias is when a person chooses a particular creed (ideology) and then looks at the world through it, and carries out propaganda and mobilization operations within it. This type of bias is so obvious that it usually expresses itself. However, this bias, although obvious, can be passed on to the recipient in subtle ways that they are not aware of. As for the unconscious latent bias, it is that a person internalizes a knowledge system with all its priorities and theses, and looks at the world through it without being aware of it.
(3) Bias toward the truth and bias toward falsehood:

A person may be biased towards what he believes to be the truth, and that is the obligation. He is also ready to test the fruit of his research, as he does not believe that his (biased) judgments are the final and absolute judgment, as his judgments are diligence, first and foremost. Perhaps one of the most prominent examples of this type of bias is the use of the method of argument and debate in our Arab Islamic heritage to know the truth and reach it. Despite the bias of the two opposing sides to what they believe to be the truth, each of them remains fully prepared to understand the other party's point of view and cooperate with it to reach the truth, which remains the supreme goal of the debate, far from fanaticism and selfishness. As for bias towards falsehood, it is for a person to bias himself and make himself the only acceptable reference. The one who is biased towards falsehood is always biased towards power and authority. He imposes his will when he is strong and victorious, and turns into a utilitarian realist who submits to others, and accepts their rulings on him without being convinced of them when he is weak and defeated, as strength is his only reference, and therefore he is constantly on the lookout, waiting for the balance of power to change in his favor.

Al-Masiri also referred to the concept of (bias within bias), meaning that the researcher is biased towards a particular cognitive model, but within this model, he focuses on and adopts certain aspects of it, and neglects the other aspects, even though they all belong to the same cognitive model.

Ali Siddiqi (2016) [30] also sought to discuss the characteristic of bias in contemporary critical discourse. The meaning of his bias refers to the backgrounds of the critical method of an ideological, religious or civilized nature whose impact is reflected on the tools of analytical practice. In other words, the researcher's critical approach is not only a procedural tool that performs the functions of leading the steps of analysis, but rather it is a cultural practice that carries with it its reference, and the claim of objectivity is not useful in denying this reference and denying its impact on the tools.

Among the powers that critical discourse can contain is the passing of values, beliefs, and philosophies in an implicit manner. Among the discourse strategies, implication and nonstatement are, and for this reason, we use the terms power, violence, and subjugation. The ordinary reader deals with the outward appearance of the discourse and neglects its innermost part with the ideological weight it carries, and thus is ready to accept the violence of direction, influence, and filler in an unconscious way.

Siddiqi (2016) explains that some researchers, most of whom are Arabs, give Western critical curricula characteristics of (universal, scientific, and absolute). The reality of these qualities is not devoid of illusion and fabrication, because the critical method is a human production to which the law of vulnerability applies like other intellectual productions, and during its formation, it is subject to the influences of the intellectual assets prevailing in its cultural environment [30].

As for Al-Hashemi's study (2014) [31], the concept of bias is based on two main considerations:

(1) The first consideration is self-aggrandizement and centering on it, as language is manipulated to create ready-made stereotypes that label the self with all the attributes of transcendence and superiority, and make it a symbol of civility, perfection and science. Here, the study refers to Abdullah Ibrahim's definition of 
concentration as "a pattern of lofty thinking that closes to the self, confines itself to a certain method, trapped in it and does not approach things except through his vision and statements, and employs all data to confirm the validity of those statements."

(2) As for the second consideration, it is the absence of the other or his belittling and marginalizing him in an attempt to exclude him, by branding him with all the features of belittling and inferiority.

The research sees that the concept of "acculturation", which corresponds to the British, is "cultural exchange" and when "the overlap of civilizations" is based on dialogue, with which the limits of prejudice and coercion are removed, as it creates a presence in which the parties are equal so that the study reaches its definition as: "The sum of phenomena resulting from continuous and direct contact between groups of individuals belonging to different cultures leads to changes in the initial cultural patterns of the group or groups".

So the term goes to denote the cross-fertilization of different cultures, hence culture is based on just participation, which carries cognitive dimensions and other ethical values [31].

Ali Abdel Raouf's study was also characterized by clarifying the danger of complete bias towards a Western taste in architecture and art, as previously mentioned above. This study confirms that this proposition is the one that comprehends the value of the past and its impact on the formation of local identity, cultural specificity and spatial personality, but it also understands the ability of the Arab creator to reject the bias of the Western project and reflect on its analysis, criticism and restructuring, in a way that makes it a contributor to the contemporary Arab vision of man and place, or rather architecture [28].

From the foregoing, the most important general characteristics of the concept of bias can be mentioned, as shown in Table 1.

Table 1. The general characteristics of the concept of bias

\begin{tabular}{|c|c|}
\hline $\begin{array}{l}\text { The } \\
\text { Studies }\end{array}$ & The most important terms \\
\hline \multirow{5}{*}{ Al-Mesiri } & Bias is deterministic indefinite. \\
\hline & Total bias, and partial bias. \\
\hline & $\begin{array}{l}\text { The conscious bias (obvious), and the } \\
\text { unconscious bias. }\end{array}$ \\
\hline & Bias with truth, bias with falsehood. \\
\hline & Bias within Bias. \\
\hline \multirow[b]{2}{*}{ Ali Siddiqi } & Subjugation by unauthorized implicit bias. \\
\hline & $\begin{array}{c}\text { The bias towards universalism and science is not } \\
\text { without exaggeration. }\end{array}$ \\
\hline \multirow[b]{2}{*}{ Al-Hashimi } & Bias is self-aggrandizing and symbolizing it. \\
\hline & $\begin{array}{c}\text { Bias is the absence and marginalization of the } \\
\text { other. }\end{array}$ \\
\hline \multirow{2}{*}{$\begin{array}{l}\text { Ali Abd } \\
\text { Raouf }\end{array}$} & $\begin{array}{l}\text { Finding a harmonious alternative instead of a } \\
\text { closed self-bias. }\end{array}$ \\
\hline & $\begin{array}{l}\text { Finding the creative alternative instead of } \\
\text { replacing the other bias. }\end{array}$ \\
\hline
\end{tabular}

\section{CASE STUDY}

The research applies its test to a group of articles that, through their criticism, directly or indirectly, indicated the concept of bias and its role in determining the features and idea of contemporary architecture in Arab cities, specifically in Dubai, as follows.

\subsection{Khalifa tower}

Tamal's study (2015) [32] explained according to critic Riley MacPhee, the towers represent suitable solutions from an environmental point of view, and this is not achieved in Khalifa tower in Dubai, where mechanical uses occupy a large area that cannot contain other useful functions, due to its decreasing area upwards, and therefore technical services occupy a quarter of the building area, which negates the sustainability characteristic of the tower, in addition to the lack of a convincing reason for the existence of such heights in Dubai, where the vast areas are sparsely urban, unlike the presence of New York City towers, which is justified in an environment crowded with people and businesses (Figure 2).

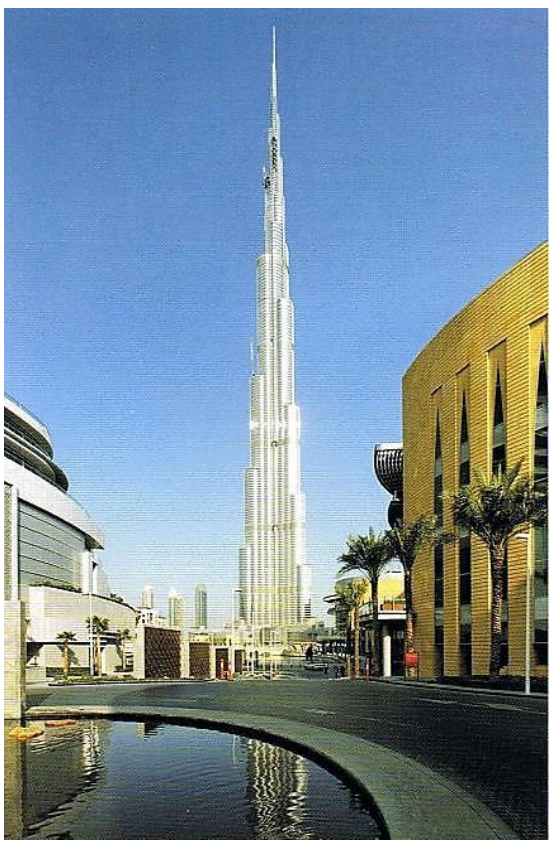

Figure 2. Khalifa Tower in Dubai

As for the formal level, McAfee claims: "Architecture must be beautiful in shape, but the formal beauty is not achieved in Khalifa tower, as the form is exaggerated in terms of length and grace."

On the other hand, critic Robert Lvy considered skyscrapers such as the Khalifa tower sustainable buildings because they accommodate a large number of people on a small area of land, which helps to save agricultural land instead of using it as built-up areas, and is useful in reducing carbon emissions resulting from the movement of transportation from and to suburbs, they also provide efficient vertical and horizontal movement systems, encourage the use of public transportation, and activate pedestrian paths.

As for the formality, Lvy says: Khalifa tower is the most elegant of its era. The curvaceous mass appears to be made up of minimal volume, and the building is curvaceous and architecturally interesting [32].

The summary of what the critics dealt with in the project appears through the bias in the functional and formal aspects of the tower. The views presented on these aspects differed between those who encourage the adoption of high buildings in architecture as unique models and those who call for maintaining urban compatibility in form and use.

From the foregoing, the most important findings of the previous study can be mentioned as in Table 2 . 
Table 2. The most important findings of the study

\begin{tabular}{ccc}
\hline $\begin{array}{c}\text { Critical } \\
\text { aspect }\end{array}$ & Lvy & MacPhee \\
\hline Formal & $\begin{array}{c}\text { Khalifa tower is the } \\
\text { most elegant and } \\
\text { exciting in the world. }\end{array}$ & $\begin{array}{c}\text { The shape of the building } \\
\text { is exaggerated in terms } \\
\text { of length and grace. }\end{array}$ \\
\hline & $\begin{array}{c}\text { The tower is } \\
\text { considered sustainable } \\
\text { to accommodate a } \\
\text { large number of } \\
\text { people in a small } \\
\text { space, which reduces } \\
\text { the built environment } \\
\text { in nature. }\end{array}$ & $\begin{array}{c}\text { An image in the city that } \\
\text { is not functionally } \\
\text { feasible, and is } \\
\text { considered unsustainable } \\
\text { because there are a large } \\
\text { number of people in the } \\
\text { same place, which poses } \\
\text { a security risk in the city. }\end{array}$ \\
\hline
\end{tabular}

Source. Prepared by the researcher based on previous data

\subsection{Dubai city}

Academic and critic Khaled Al Sultani (2013) [33] spoke about the lessons learned from the architecture of Dubai through his review of the book "Architecture in the Emirates" by the American critic Philip Jodidio, issued by the German "Taschen" publishing house, 2007. He indicated that the connotations of the book's title go beyond the limits of its literal meaning, to include what has been accomplished in the cities of the Emirates, in addition to the "effervescence" of architectural activity in other Gulf cities. It means an architectural activity for a wide geographical area, an activity that seeks to establish a "ground" for that interesting creative lesson, characterized by its event uniqueness and its exceptionality in the speech. But it remained a lesson that was not followed diligently by our Arab architectural critics, and those interested in cultural affairs, although it is a very important lesson, whether in terms of theorizing or practice. Many can learn from it, or emulate it, and they can draw lessons from it, away from the illusions of cultural "centralization", which have always confused visions and, without right, diminished the achievement of others.

Al-Sultani also refers to what architect Zaha Hadid went so far in presenting her proposal for the meaning of the administrative building today, and of course to define its features, those features that have no connection, as it turned out, to what was familiar and common. In the "Office Towers Complex" in Dubai, located in the Business Bay near the Dubai tower, modernist architecture shows its perceptions of the building in a striking and shocking form. It is a cubic block with a height of 93 meters, penetrated by a "recess" of free form on one side, and a "crack" descending from the top towards the borders of the lower floors on the other side. Through this strange body, the designer tends to attend what she calls "connectivity" and "uniqueness", which in her opinion can create a charming view towards the Gulf and the neighborhoods, while providing a very suitable environment for work, which makes the building's users to show the maximum of their professional capabilities [33].

In contrast to this proposition, researcher Al-Naeem (2010) [34] believes that the architecture of the Arab Gulf in general and Dubai, in particular, is based on both capitalist real estate investment thought and its adoption of high technology and its neglect of the natural environment in most of its projects, and its reliance on expensive technological means to achieve experiences of sustainable architecture that are for more propaganda purposes, on the expenses of compatible environmental solutions (especially in a society that consumes technology and is unable to produce or even localize it), and the economic-political dimension is dominant over the deep structure of this model, thus marginalizing the social dimension, which necessitates a superior tendency in the decision-making structure and in response to the desire of the dominant elite.

This can be explored in giant housing tower projects, as in the vertical city project with a height of more than two miles or the dynamic rotating architecture project, which represents the most extreme degree of investment technology propaganda, the Dubai tower project (the highest tower in the world), and the luxurious architecture represented in the Al Arab Tower Hotel, that is the most expensive and the highest hotel tower in the world.

Another tendency of this trend can be explored in projects of copying, transferring or resettling heritage and history, as happened with the (Dubai Cities) project. Its idea is to collect the important historical monuments of the oldest and most important five Arab cities, namely Baghdad, Damascus, Marrakesh, Cairo and Beirut in one residential and commercial entertainment project, and the Taj Mahal project in Dubai and the Great Pyramid of Dubai. This method of assembling historical monuments from different places, references and times are similar to the method of amusement and entertainment cities developed in the deserts of the American West.

From this context, the writer also extrapolates the metaphorical cosmic architecture that emphasizes the principles of formal and objective metaphor from ecological and biological cosmic phenomena with varying degrees of analogy and abstraction and in the light of contemporary complex sciences and benefiting from the informatics and computer revolution in making the design and implementation of these projects possible [34].

From the above, the results of applying the selected samples for measurement can be analyzed as in Table 3 .

Table 3. Analysis results of the selected samples

\begin{tabular}{cc}
\hline $\begin{array}{c}\text { Criticism of Khaled Al- } \\
\text { Sultani }\end{array}$ & $\begin{array}{c}\text { Criticism of Mashari Al- } \\
\text { Naeem }\end{array}$ \\
\hline $\begin{array}{c}\text { A natural development of } \\
\text { urban production }\end{array}$ & $\begin{array}{c}\text { Urgent development of urban } \\
\text { production }\end{array}$ \\
\hline $\begin{array}{c}\text { Adopting cultural exchange } \\
\text { in presenting project ideas }\end{array}$ & $\begin{array}{c}\text { Relying only on Western } \\
\text { culture }\end{array}$ \\
\hline Unique creative products & $\begin{array}{c}\text { Consumer marketing } \\
\text { advertising products }\end{array}$ \\
\hline $\begin{array}{c}\text { The importance of learning } \\
\text { from them and drawing } \\
\text { lessons }\end{array}$ & $\begin{array}{c}\text { A superior tendency that } \\
\text { satisfies the desire of the } \\
\text { dominant elites }\end{array}$ \\
\hline $\begin{array}{c}\text { Its buildings have become a } \\
\text { visual icon in Arab cities }\end{array}$ & $\begin{array}{c}\text { Its buildings have become } \\
\text { strange and globalized in Arab } \\
\text { cities }\end{array}$ \\
\hline Source. Prepared by the researcher based on previous data
\end{tabular}

\subsection{Discussion}

From the foregoing in Tables 2 and 3 above, the bias of each of the critics concerning contemporary architectural projects appears in the selected applied sample, where each of the critics (Levy and Al-Sultani) shows a positive bias in which they move away from isolation and interruption and work to find an innovative alternative and harmonious rather than closed self-bias, which is the partial bias in criticism. While critics (MacPhee and Al-Naeem) rely on a conscious and clear bias towards local identity as being able to distinguish and not the other, which represents a total bias in architectural 
criticism. Thus, the validity of the hypothesis is achieved in determining the characteristics or concepts of bias related to architectural criticism.

\section{CONCLUSIONS}

From the foregoing, several conclusions can be drawn from the research, which are:

(1) Architectural criticism should derive from the theoretical dimension extending from the past to the present, it must proceed from a historical narrative, based on the active role of the social and political components of the current architecture. Criticism explains the role of the developed ideology that made architecture a part of the stages of history and its consequences.

(2) Contemporary architecture is compatible with cultural domination and is also not capable of following a single critical form because of the possibilities imposed by time and place.

(3) There is great disagreement among architectural critics about what architectural criticism is today.

(4) Any architectural criticism is likely to fall into error, like any other artistic criticism. Criticism is an imposition and not a definitive ruling, and this is related to the philosophical definition of the arts at present

(5) Understanding the architectural form is the first step to criticizing it, and this understanding stems from a comprehensive knowledge of architectural history.

(6) Realizing the inevitability of bias is the first step to overcoming it. The critical mind is deficient but effective, and it confronts the complex reality and interacts with it. It keeps, excludes, abstracts, denies, corrects, synthesizes and formulates its cognitive models through which it perceives architecture. This awareness of the inevitability of bias helps us to understand behavior based on those cognitive models that the mind formulates through its interaction with reality. Criticism of bias should not stop at the practical side only but should focus on the entire theoretical structure that produces this bias.

(7) The claim about local identity in architecture and the bias of the curricula and concepts associated with it is not definitive and does not benefit the meaning of closing and withdrawing from oneself. That is, it is not an abolition of the possibilities of benefit or the existence of common things. To say that all of that is abolished is a statement that contradicts the facts of thought and history.

(8) Awareness of difference is what is absent from our current civilization to achieve the desired real renaissance in Arab and Islamic architecture, because in the absence of this condition, diligence leading to creativity is absent, and it is replaced by the imitation that leads to following on.

(9) In general, it does not make sense for a person or any entity to move without biases. Bias is a state of adoption of ideas and belief in them, and even if a person does not announce them directly, it is the engine of all his behaviors. Therefore, bias is required and logical, provided that the behavior of justice and fairness do not deviate from it. Justice and fairness enable the mind to point out flaws, distinguish between right and wrong, and evaluate situations without falling into fanaticism or the so-called blind bias. As for the negative attitudes of some critics, that they are not biased or neutral, this makes them accused that their ideas are gelatinous and there is nothing to base them on

\section{REFERENCES}

[1] Gilovich, T., Griffin, D., Kahneman, D. (Eds.). (2002). Heuristics and BIASES: The Psychology of Intuitive Judgment. Cambridge University Press, 430-454. https://doi.org/10.1017/CBO9780511808098

[2] Aref, N.M. (2002). Development from a Renewed Perspective: Bias for Postmodern Globalization, Center for Political and Strategic Studies. 1st Edition, Cairo, 3738.

[3] Badawi, A.Z. (1993). A Dictionary of Social Sciences Terms. Library of Lebanon Publishers, 39-40.

[4] Al-Saleh, M. (1999). The Comprehensive Dictionary, Dictionary of Social Sciences Terms. Dar Alam AlKutub, Riyadh, Saudi Arabia, 65-66.

[5] Hariri, A.R. (2010). In Foundations and Methodology of Research, Scientific Research Blog, Electronic Version.

[6] Attia, A.H. (2018). Abdel Wahab El-Mesiri, a study in his epistemological biography and his criticism of the values of Western modernity, the Islamic Center for Strategic Studies, first edition, p. 23. https://www.iicss.iq/?id=3283.

[7] Seddiqi, A. (2011). The Concept of Bias according to Abdel Wahab El-Mesiri, Kalima Magazine, Al-Kalima Forum for Studies and Research, Issue 73, AD. http://kalema.net/home/article/print/1033.

[8] McLeod, S. (2018). Cognitive Dissonance. http://www.simplypsychology.org/cognitivedissonance.html.

[9] Yamagishi, T., Jin, N., Miller, A.S. (1998). In-group bias and culture of collectivism. Asian Journal of Social $\begin{array}{lll}\text { Psychology, } & 1(3): & 315-328 .\end{array}$ https://doi.org/10.1111/1467-839x.00020

[10] Nebel, J.M. (2015). Status quo bias, rationality, and conservatism about value. The University of Chicago Press. https://doi.org/10.1086/678482

[11] Cherry, K. (2020). Bandwagon Effect as a Cognitive Bias. https://www.verywellmind.com/what-is-thebandwagon-effect-2795895.

[12] Cherry, K. (2017). what is the projection bias? https://www.explorepsychology.com/projection-bias/.

[13] The Decision Lab. What is the Anchoring bias? https://thedecisionlab.com/biases/anchoring-bias/.

[14] Alicita Rodriguez. (2019). What is the Frequency Illusion? https://news.ucdenver.edu/what-is-thefrequency-illusion/

[15] Pfabigan, D.M., Tran, U.S. (2015). Behavioral and physiological bases of attentional biases: paradigms, participants, and stimuli. Participants and Stimuli, Frontiers in Psychology, 5-10. https://doi.org/10.3389/fpsyg.2015.00686

[16] Phung, A. (2010). Behavioral Finance: Key concepts overreaction and availability bias. p. 10 . http://i.investopedia.com/inv/pdf/tutorials/BehavioralFi nance.pdf.

[17] Mather, M., Johnson, M.K. (2000). Choice-supportive 
source monitoring: Do our decisions seem better to us as we age? Psychology and Aging, 15(4): 596-606. https://doi.org/10.1037/0882-7974.15.4.596

[18] Pronin, E., Lin, D. Y., Ross, L. (2002). The bias blind spot: Perceptions of bias in self versus others. Personality and Social Psychology Bulletin, 28(3): 369-381. https://doi.org/10.1177/0146167202286008

[19] Edwards, W. (1982). Conservatism in Human Information Processing (excerpted). In Daniel Kahneman, Paul Slovic and Amos Tversky, Judgment under uncertainty: Heuristics and biases, New York, Cambridge University Press.

[20] Naval, E. (2019). The Curse of Knowledge. https://digitallearning.arizona.edu/news/curseknowledge.

[21] Baron, J., Hershey, J.C. (1988). Outcome bias in decision evaluation. Journal of Personality and Social Psychology, 54(4): 569-579.

[22] Elton, E.J., Gruber, M.J., Blake, C.R. (2015). Survivor bias and mutual fund performance. The Review of Financial Studies, 9(4): 1097-1120.

[23] Tabarak, A., Fahad M. (2019). Anchoring \& Stereotyping Biases Considering Different Classes in Our Society. $\quad$ p. 3. http://dx.doi.org/10.13140/RG.2.2.15926.45121

[24] Milgram, S. (1963). Behavioral Study of obedience. The Journal of Abnormal and Social Psychology, 67(4): 371378. https://doi.org/10.1037/h0040525

[25] Think Economic and Financial Analysis. (2002). What is Salience Bias? https://think.ing.com/articles/what-issalience-bias.

[26] El-Mesiri, A.W. (1996). The Problem of Bias: An Epistemological Vision and a Call to Ijtihad. Volume 1, 2nd Edition, The International Institute of Islamic
Thought, Arabic Edition, 423-422. https://www.goodreads.com/book/show/6240181.

[27] Waziri, Y.H. (1986). The Paradise Theory in Islamic Architecture, Building World Magazine, No. 68, Center for Planning and Architectural Studies, Cairo, Arabic Edition, 23-24. https://www.academia.edu/30894435.

[28] Abdel Raouf, A. (2016). Critical Articles in Egyptian Architecture: Conceptual Problems, Critical Theses, Urban Issues, Arabic Edition, pp. 23, 27, 28, 31. https://www.researchgate.net/publication/332141644.

[29] Harfi, S. (2009). Dialogues with Abdel Wahab El-Mesiri, Culture and Method, Dar Al-Fikr, Damascus, Arabic Edition, $\quad$ pp. 307-325. https://www.goodreads.com/ar/book/show/7695584.

[30] Seddiqi, A. (2016). The problem of bias in contemporary Arab criticism, critical analytical study. Kunooz Al Maarifa House for Publishing and Distribution, Arabic Edition. https://jamalon.com/ar/1023913.html.

[31] Al-Hashemi, Gh. (2014). The problem of bias in contemporary Arab thought. Journal of the College of Education, Wasit, Arabic Edition, 15: 269-271. https://doi.org/10.31185/eduj.Vol1.Iss15.373

[32] Al-Farid, T.R. (2015). Standards of beauty and methods of measurement in contemporary architecture. Ph.D. thesis, pp. 152-153, 157-158. https://www.pinterest.com/pin/470415123572968407/.

[33] Al-Sultani, Kh. (2013). The Verb and Text of Architecture, an article entitled: A Lesson from Dubai, published by Dar Al Mada Al Thaqafi, Arabic Edition. https://www.goodreads.com/book/show/20736213.

[34] Al-Naeem, M. (2010). The Book of Urbanism, Published by Al-Sharqiya Literary Club, Arabic Edition, Saudi $\begin{array}{llll}\text { Arabia, } & \text { p. 209, } & \end{array}$ https://uqu.edu.sa/aamajrashi/70961. 